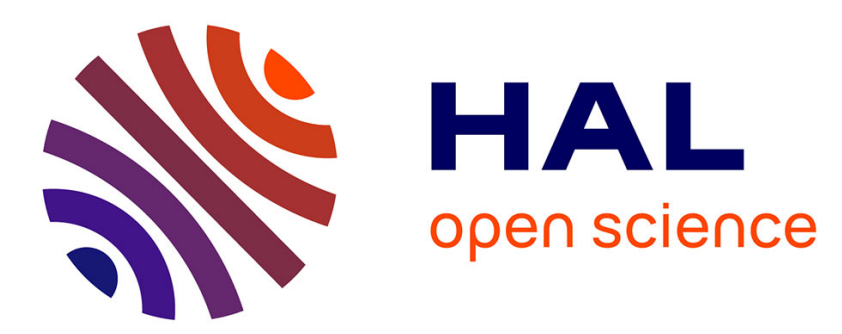

\title{
Gonadal lesions of female sea urchin ( after exposure to the polycyclic aromatic hydrocarbon phenanthrene
}

\author{
S. Schäfer, A. Köhler
}

\section{To cite this version:}

S. Schäfer, A. Köhler. Gonadal lesions of female sea urchin ( after exposure to the polycyclic aromatic hydrocarbon phenanthrene. Marine Environmental Research, 2009, 68 (3), pp.128. 10.1016/j.marenvres.2009.05.001 . hal-00499562

HAL Id: hal-00499562

https://hal.science/hal-00499562

Submitted on $10 \mathrm{Jul} 2010$

HAL is a multi-disciplinary open access archive for the deposit and dissemination of scientific research documents, whether they are published or not. The documents may come from teaching and research institutions in France or abroad, or from public or private research centers.
L'archive ouverte pluridisciplinaire HAL, est destinée au dépôt et à la diffusion de documents scientifiques de niveau recherche, publiés ou non, émanant des établissements d'enseignement et de recherche français ou étrangers, des laboratoires publics ou privés. 


\section{Accepted Manuscript}

Gonadal lesions of female sea urchin (Psammechinus miliaris) after exposure to the polycyclic aromatic hydrocarbon phenanthrene

S. Schäfer, A. Köhler

PII:

S0141-1136(09)00053-1

DOI:

10.1016/j.marenvres.2009.05.001

Reference:

MERE 3338

To appear in:

Marine Environmental Research

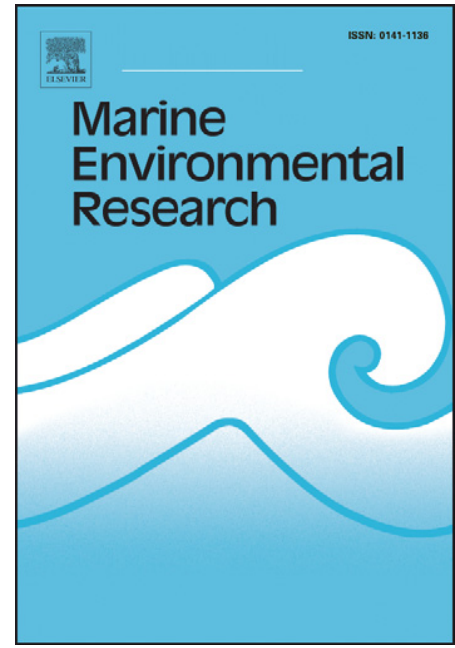

Received Date: $\quad 12$ November 2008

Revised Date: $\quad 29$ April 2009

Accepted Date: $\quad 7$ May 2009

Please cite this article as: Schäfer, S., Köhler, A., Gonadal lesions of female sea urchin (Psammechinus miliaris) after exposure to the polycyclic aromatic hydrocarbon phenanthrene, Marine Environmental Research (2009), doi: 10.1016/j.marenvres.2009.05.001

This is a PDF file of an unedited manuscript that has been accepted for publication. As a service to our customers we are providing this early version of the manuscript. The manuscript will undergo copyediting, typesetting, and review of the resulting proof before it is published in its final form. Please note that during the production process errors may be discovered which could affect the content, and all legal disclaimers that apply to the journal pertain. 


\section{Gonadal lesions of female sea urchin (Psammechinus miliaris) after}

\section{exposure to the polycyclic aromatic hydrocarbon phenanthrene}

4 Schäfer S., Köhler A.*

6 Alfred Wegener Institute for Polar and Marine Research in the Helmholtz Association, Am

7 Handelshafen 12, 27570 Bremerhaven, Germany

$9 \quad{ }^{*}$ Corresponding author

11 Prof. Dr. Angela Köhler

12 Phone: 0049 (0) 47148311407

13 Fax: 0049 (0) 47148311425

14 Email: Angela.Koehler@awi.de

15

Alfred Wegener Institute for Polar and Marine Research

Am Handelshafen 12

27570 Bremerhaven

19 Germany

\section{Abstract}

22 Histopathological alterations in the reproductive tissue of the female sea urchin 23 Psammechinus miliaris after exposure to the polycyclic aromatic hydrocarbon (PAH) 24 phenanthrene were investigated using light microscopy. Sexually mature sea urchins were 25 exposed to $500 \mathrm{\mu g} \mathrm{L}^{-1}$ phenanthrene for 20 days. A severe disorganisation of the acinal 26 structure of the gonads was observed in phenanthrene-treated animals, mainly as a result of aggregates of degenerating previtellogenic oocytes. Growth and maturation of previtellogenic 

31

oocytes were inhibited, whereas there were no obvious effects on vitellogenic oocytes and

29 mature ova. The acinal wall showed signs of fibrosis as well as dilation of the two epithelial 30 layers. Phenanthrene severely affected the reproductive function of the sea urchins since a

\section{Introduction}

Many environmental pollutants have been shown to interfere with reproductive function in animals (Haschek and Rousseaux, 1998). Sea urchin gametes and embryos are widely used for evaluating biological effects of contaminants in marine environments (Greenwood, 1980; Kobayashi, 1980; Hose, 1985; Klöckner et al., 1985; U.S. EPA, 1993). However, the underlying mechanisms resulting in reduced reproductive success of adult marine invertebrates and of sea urchins, in particular, are hardly investigated (Au et al., 2001a; Au et al., 2001b). Histopathology is a well established tool for the identification of tissue and cellular injury. Histopathological biomarkers and cellular changes in the reproductive tissue can be used to gain a better understanding of the adverse effects of environmental pollutants on reproduction (Au, 2004; Dietrich et al., in press).

Sea urchins play a key role in benthic communities of coastal waters and changes in sea urchin populations have led to major alterations in marine community structure (Scheibling, 1986; Steneck et al., 2002). Psammechinus miliaris is a common echinoid found at depths of up to 100 metres in the Atlantic from Scandinavia to the Azores including the North Sea and the Baltic Sea (Boschma et al., 1932; Campbell, 1977). This species has been used as a test 
organism in fertilisation and embryo development assays (Klöckner et al., 1985; Caldwell et al., 2002; Caldwell et al., 2004). In the past years $P$. miliaris has gained interest as promising candidate for aquaculture especially in polyculture with the Atlantic salmon (Kelly et al., 1998).

Sea urchins are dioecious and due to their pentaradial body organisation they possess five gonads with separate gonadopores (Westheide and Rieger, 1996). Functional units of the gonads are the so-called acini which are surrounded by a multi-layered acinal wall (Palmer Wilson, 1940). Germ cells are formed at the germinal epithelium of the acinal wall and migrate towards the lumen of the acinus during maturation (e.g. Byrne, 1990; Walker et al., 1998; Kelly, 2000). During oogenesis oocytes undergo meiotic divisions and an increase in size to form mature ova. In the ovary oogenic cells, namely oogonia, previtellogenic and vitellogenic oocytes can be distinguished from mature ova by the presence of the germinal vesicle (GV) containing a prominent nucleolus (Chatlynne, 1969). Further, nutrients are supposed to be transferred from the somatic cells of the gonads, the nutritive phagocytes (NPs), to the gametogenic cells (Walker et al., 1998). Therefore, vitellogenic oocytes and mature ova have - in contrast to the early maturational stages, the oogonia and previtellogenic oocytes - yolk granules in their cytoplasm. In most sea urchin species living at higher latitudes gametogenesis is a single annual event with one spawning period (Walker et al., 1998). At the west coast of Scotland Psammechinus miliaris is reported to have a clearly defined reproductive cycle with a single spawning period in June and July (Kelly, 2000).

There are only few studies investigating the effects of chemicals on gonadal tissue of sea urchins. At the light microscopical level histopathological lesions of sea urchin gonads are 80 reported by Vashchenko and Zhadan (1993), Vaschenko et al. (2001) and Vashchenko et al. 81 (2001) in areas of Peter the Great Bay (Sea of Japan) polluted with heavy metals. 82 Histopathological alterations of spermatogenesis in the sea urchin Anthocidaris crassipina 
83 after experimental exposure to phenol and cadmium were investigated by electron

85

86

84 microscopy (Au et al., 2001b; Au et al., 2003).

Polycyclic aromatic hydrocarbons (PAH) are lipophilic organic compounds which are ubiquitously found in the marine environment. Phenanthrene is a low molecular weight, 3ring $\mathrm{PAH}$ and is classified as a priority pollutant by the United States Environmental Protection Agency (US EPA). It is an important petroleum-source PAH and a major component of the total content of PAH compounds in the marine environment. PAHs are known to induce degeneration of oocytes and ovarian lesions in several species (Mytilus edulis - Aarab et al., 2004; Littorina littorea - Cajaraville et al., 1990; mammals - Sakamaki, 2003). Degeneration and absorption of oocytes, so called oocyte atresia, is a normal physiologic event which may become pathologic after chemical exposure (Blazer, 2002; Dietrich et al., in press). Furthermore, contamination with PAHs has been shown to be associated with an increased accumulation of lipofuscin in marine organisms (Krishnakumar et al., 1994; Krishnakumar et al., 1997; Au et al., 1999; Au, 2004). Lipofuscin, also known as age pigment, is widely regarded as end product of protein and lipid peroxidation due to oxidative stress (Au et al., 1999; Au, 2004; Terman and Brunk, 2004). In the sea urchin Lythechinus variegatus phenanthrene significantly retarded embryo development at environmentally relevant concentrations (Steevens et al., 1999). In Lythechinus anemensis phenanthrene disrupted axial development in embryos in a dose-dependent fashion which could be linked to nuclear accumulation of the protein $\beta$-catenin (Pillai et al., 2003). Pillai et al. (2003) have shown that among five investigated PAHs phenanthrene was most potent in causing exogastrulation in sea urchin embryos.

The aim of the present study was to give a detailed description of the histopathological alterations of the reproductive tissue of the female sea urchin Psammechinus miliaris after exposure to phenanthrene. The findings are compared with effects of hydrocarbons on the reproductive tissue of other aquatic invertebrates. Changes of the general acinal structure, 
111 effects on the different developmental stages of oocytes and the nutritive phagocytes, as well

as alterations of the acinal wall are described. Lipofuscin is identified and quantified in the tissue and its usefulness as biomarker of pollutant exposure in the gonads of sea urchins is discussed. Histopathological alterations of the gonads such as aggregates of degenerating oocytes, the percentage of degenerating oocytes, lipofuscin accumulation and dilation of the acinal wall are quantitatively or semi quantitatively assessed. Furthermore, the gonad weight and the gonadosomatic index in the different treatments are compared.

\section{Material \& Methods}

\section{$\underline{3.1 \text { Animal collection and experimental set up }}$}

Adult Psammechinus miliaris were collected with a beam trawl close to the Island of Sylt (Germany) at $55^{\circ} 02,40 \mathrm{~N}$ and $08^{\circ} 27,25 \mathrm{E}$ in May 2006. They were separated by sex and 123 transported to the laboratory in Bremerhaven. In a range finding experiment, sea urchins 124 were exposed to set concentrations of $1,3,12,42,145$ and $500 \mu \mathrm{g} \mathrm{L}^{-1}$ phenanthrene, to $1250.01 \%$ acetone, as the solvent control, and to sea water only for 10 days. Each treatment 126 consisted of two replicate tanks (glass vessels with a volume of $1.5 \mathrm{~L}$ ) with 4 sea urchins 127 each. Since no mortality occurred in this preliminary experiment $500 \mu \mathrm{g} \mathrm{L}^{-1}$ phenanthrene 128 was chosen as sublethal test concentration for the subsequent experiment. Female sea 129 urchins of a minimum size of $20 \mathrm{~mm}$ horizontal test diameter were selected and acclimatized 130 to experimental conditions for 4 weeks. Sea urchins were exposed to $500 \mu \mathrm{g} \mathrm{L}^{-1}$ 131 phenanthrene (dissolved in acetone), to $0.01 \%$ acetone, as solvent control, and to sea water 132 only $\left(9 \pm 0.5^{\circ} \mathrm{C}, 33 \pm 1 \mathrm{PSU}\right.$, continuous aeration). Duration of the experiment was limited to 13320 days to terminate the test before the natural spawning period of the animals had started. 134 Each treatment consisted of 3 replicate tanks (16 L glass aquaria) containing 10 sea urchins 135 each. Water was renewed every third day and phenanthrene or solvent were added at the 136 respective concentrations. Sea urchins were fed with fresh spinach. Mortality of sea urchins 137 was checked daily. 


\subsection{Sampling}

For comparison of growth parameters, 24 samples were taken at the beginning (day 0 ) and 30 replicate samples per treatment were taken at the end of the exposure period (day 20). Animals were weighed and horizontal and vertical test diameters were measured with a calliper. The animals were dissected and the gonads were removed and weighed. The gonad index (Gl) was calculated as the wet weight of the gonad divided by the total somatic wet weight of the sea urchin expressed as a percentage.

For histopathology, six replicate samples were taken per treatment at day 20. Gonads were immediately fixed in Baker's Formol calcium (4\% formaldehyde and $2 \%$ calcium acetate) over night. On the next day, the samples were transferred into gum sucrose $(30 \%$ sucrose and $1 \%$ gum arabicum) and stored at $4^{\circ} \mathrm{C}$.

\subsection{Embedding, sectioning and staining}

Gonad samples were dehydrated with an increasing series of acetone of $70 \%$ and $100 \%$ and embedded in methacrylate as described elsewhere (Köhler, 2004). After the embedding procedure, tissue blocks were left to dry for at least two days and serial sections of $2 \mu \mathrm{m}$ thickness were cut on a microtome (HM Leica RM 2145).

The sections were stained with hematoxylin and eosin (H\&E) for demonstration of eosinophilic and basophilic structures, with Alcian Blue/PAS for neutral and acidic mucopolysaccharides (glycosaminoglycans) such as hyaluronic acid, chondroitin sulfate and sialic acids, with Schmorl's staining procedure for lipofuscin, and with Picrosirius for collagen.

Most H\&E staining procedures proved to be insufficient possibly due to the low eosinophilia of the tissue. The most appropriate method was the one described by Cerri and Cerri-Sassi (2003) which is appropriate for methacrylate embedded tissue. 
167 For the Alcian Blue/PAS staining procedure sections were first stained with Alcian Blue according to (Lendrum et al., 1972). Then the slides were placed overnight in aldehyde blocking solution ( $2 \%$ sodium chlorite in $6 \%$ acetic acid). They were washed in running tap water for $10 \mathrm{~min}$., rinsed in distilled water for $2 \mathrm{~min}$., placed in $1 \%$ periodic acid for $10 \mathrm{~min}$. and rinsed again in distilled water for $5 \mathrm{~min}$. Then the sections were counterstained in Schiff's reagent for 20 min., bleached in sulfurous acid for 2 min., washed again in distilled water for $5 \mathrm{~min}$. and stained with Gill's hematoxylin for $15 \mathrm{~min}$. The sections were blued in running tap water for 10 min., rinsed in distilled water for 2 min., air dried and mounted with Euparal. The procedure results in blue staining of acidic mucopolysaccharides, magenta staining of neutral mucopolysaccharides and in a blue/purple staining of a mixture of acidic and neutral mucopolysaccharides. Nuclei appear deep blue.

For the identification of collagen fibres sections were stained with Picrosirius according to the method described by Cerri and Cerri-Sassi (2003) which resulted in homogeneous pink staining of collagen.

\subsection{Microscopy}

Slides were viewed with a microscope (Axioscope, ZEISS) and images were taken with a camera (MRc, ZEISS) coupled to a computer equipped with the software AxioVision (Vers. 4.6.3.0, ZEISS). 
195 Tissue sections stained with the Schmorl's method were quantitatively and objectively assessed for lipofuscin content using computer assisted image analysis. The image analysis consisted of the above described microscope and camera and the software KS300 (Vers. 3.0, ZEISS). Image intensity was measured using grey values from 1 (clear, white) to 255 (dark, black). Three black and white images were randomly taken from each duplicate section of gonadal tissue (6 measurements per individual) with a 10x objective. In a special macro individual ovarian acini were marked as 'region of interest'. Lipofuscin granules within the defined acini were identified with the aid of a threshold function which discriminates the darker stained lipofuscin granules from the background. The software computed the areal density of lipofuscin [\%] within the marked acinus ('region of interest') and mean values for each individual were calculated.

Further quantifications were performed on sections stained with Alcian Blue/PAS method. Aggregates of degenerating oocytes were quantified by applying an eyepiece graticule with a 100 squares grid $(10 \times 10)$ as an overlay. The number of squares lying on the acinus and the number of squares lying on aggregates of degenerating oocytes were counted at $400 x$ magnification. In each duplicate section five areas were randomly chosen (10 measurements per animal). The areal density of oocyte aggregates [\%] within the acini was calculated. Dilation of the acinal wall was semi quantitatively assessed. For this purpose, in each sample 5 randomly chosen areas were graded according to a scaling scheme from 0 (no change) to 2 (severe alteration) at $100 \times$ magnification. Degenerating previtellogenic oocytes identified by fading and vacuolisation of the cytoplasm, cell lysis and disruption of the membrane of the germinal vesicle at $600 \times$ magnification were counted. Oogonia were not considered due to their small size and the resultant difficulty in diagnosis. 100 randomly selected previtellogenic oocytes were counted per sample and the data are presented as a percentage.

\subsection{Statistics}

Residuals were tested for normality and variance homogeneity (Levene's test). Data on gonad weight and gonad index were box cox-transformed and a one-way ANOVA with Tukey 
223 HSD as post-hoc test were run. The data for aggregates of degenerating oocytes and

lipofuscin content were square-root transformed. For the data on histopathology a one-way ANOVA was run with the Holm-Sidak method as post-hoc test. In case of non-normal data a Kruskal-Wallis ANOVA on ranks with a Dunn's test as post-hoc test was used. The significance level was set at $p<0.05$. For the growth data tests were run with JMP (Version 7.0, SAS Instiute Inc.) while histopathological analysis was done with Sigma Stat (Version 3.0.1, SPSS, 1992-2003).

\section{Results}

\section{$\underline{4.1 \text { Gonad weight and gonad index }}$}

During the 20 day exposure period no mortality occurred among the test animals. Individual gonad weight was highly variable in all treatments (Table 1). Yet, gonad weight as well as gonad index were significantly reduced after phenanthrene exposure. In the solvent control gonad weight was also reduced but not significantly different from controls. Somatic size (horizontal and vertical test diameters) and somatic weight were not different at the beginning and at the end of the experiment as well as between treatments.

\subsection{Alterations of the general gonad structure}

In control animals, acini of the gonads were characterized by the presence of oocytes and nutritive phagocytes (NP) surrounded by a relatively thin multilayered acinal wall (Figure $1 \mathrm{a}$ ). Oocytes at different developmental stages were present with the oogonia and previtellogenic oocytes (Figure $1 \mathrm{~b}$ ) preferably found close to the acinal wall and the vitellogenic oocytes (Figure $1 \mathrm{c}$ ) and mature ova (Figure $1 \mathrm{~d}$ ) in the lumen of the acini. The occurrence and frequency of the different oogenic stages varied depending on the reproductive stage of the animal as well as in the different acini of each individual. The NPs formed a meshwork inside of the acini which was more or less visible depending on the reproductive stage of the animal and the treatment. 
At the beginning of the experiment (day 0$)$ test animals $(n=10)$ were in the premature stage

according to the classification of the reproductive stages by Byrne (1990) and Kelly (2000). The animals were partly spawned which was observed by empty spaces which had been occupied by oocytes before. At the end of the experiment (day 20) the sea urchins in the three treatments were still, except of one control animal, in the premature stage and partially spawned (Figure $1 \mathrm{a}$ ). The one control animal was in the recovery period.

In phenanthrene-exposed animals, the acinal structure was severely affected: Early developmental stages of oocytes were no longer found close to the acinal wall but spread in the acinal lumen, the meshwork of NPs appeared disrupted and aggregates of degenerating previtellogenic oocytes were found in the acini (Figure $2 \mathrm{a}, \mathrm{b}$ ). Control animals hardly showed any aggregates of degenerating oocytes while in phenanthrene-exposed animals these aggregates filled large areas of most of the acini. The areal density of these aggregates was significantly increased in phenanthrene-treated animals in comparison to the control and the solvent control groups (one-way ANOVA, $p=0.006$, Figure 3 a). Remarkably, less vitellogenic oocytes were found in the gonads of animals exposed to phenanthrene in comparison to controls.

Lipofuscin identified as irregularly shaped and heterogeneously textured blue granules in sections stained with the Schmorl's technique was found in the acini (Figure $4 \mathrm{a}, \mathrm{b}$ ). High amounts of lipofuscin were localized in extracellular spaces in the acini and inside of NPs (Figure $4 \mathrm{a}, \mathrm{b}$ ). In addition, lipofuscin was found in epithelial cells of the acinal wall and in conjunction with immune cells, the so called coelomocytes, outside of the acini (Figure $4 \mathrm{a}$ ). 274 No lipofuscin was observed in oocytes. Indeed, early developmental stages of oocytes can 275 hardly be identified in sections stained with the Schmorl's technique due to their small size 276 and the lack of a counterstain. Lipofuscin deposition in oogonia and previtellogenic oocytes can, therefore, not be excluded. Overall, lipofuscin content was increased but not 
278 significantly different in phenanthrene-treated animals (one-way ANOVA, $p=0.068$, Figure 3

1

2

3

4280

5

6

7

8

9

10 b).

\subsection{Effects on germ and somatic cells}

In all treatments, oogonia, previtellogenic and vitellogenic oocytes as well as mature ova were found in the gonads. Previtellogenic oocytes are usually localized close to the acinal wall. Morphologically, they are characterized by a large germinal vesicle, a high nucleus to cytoplasmic ratio and their small size in comparison to later developmental stages. Their cytoplasm is stained blue in H\&E and Alcian Blue/PAS (Figure 1 b). Vitellogenic oocytes, on the other hand, accumulate PAS+ material in the cytoplasm with ongoing maturation visible as pink granules in the Alcian Blue/PAS stained sections. Vitellogenic oocytes are larger and their nucleus to cytoplasmic ratio is reduced in comparison to previtellogenic oocytes (Figure $1 \mathrm{c}$ ). They also possess a large germinal vesicle which breaks down to form ripe ova (Figure $1 \mathrm{~d})$ accumulating in the acinal lumen of mature animals.

We could not detect pathological changes of mature ova and vitellogenic oocytes while previtellogenic oocytes were often degenerating after maternal exposure to phenanthrene. Degenerating oocytes were characterized by fading and vacuolisation of the cytoplasm as well as cell lysis. Further, infoldings of the nuclear membrane of the GV occurred which was followed by disruption of the nuclear membrane (Figure $2 \mathrm{c}$ ). The nucleolus appeared to be normal. No pyknosis or karyomegaly of the GV was identified. In comparison to control samples, cell size of previtellogenic oocytes seemed to be reduced. Oogonia were not studied in detail due to their small size and the resultant difficulty in diagnosis of cellular alterations.

Degenerating previtellogenic oocytes identified by fading and vacuolisation of the cytoplasm, cell lysis and / or infoldings and disruption of the nuclear membrane were quantified in the gonadal tissue (Figure $3 \mathrm{c}$ ). In phenanthrene-treated animals $78 \%$ of the previtellogenic 
oocytes were classified as degenerating based on the above mentioned criteria, whereas in controls $24 \%$ degenerating previtellogenic oocytes were found. In the solvent control group the frequency of degenerating oocytes was quite variable with a few animals exhibiting high amounts of degenerating oocytes. However, differences were only significant between the control group and phenanthrene-treated animals (one-way ANOVA, $p=0.01$, Holm-Sidak).

\section{Discussion}

\subsection{Alterations of the acinal wall}

The acinal wall is usually composed of an inner and an outer layer of epithelial cells which are characterized by their basophilic nuclei. Depending on the plane of the tissue section at least one additional layer is visible being stained pink with $\mathrm{H} \& \mathrm{E}$ as well as with the Picrosirius method indicating the presence of collagen fibres (Figure $4 \mathrm{c}$ ).

In phenanthrene-exposed animals the two epithelial layers were often separate from each other (Figure $4 \mathrm{~d}, \mathrm{e}$ ). Often this dilation was concomitant with an increased formation of collagen between the epithelial layers and augmentation of basophilic material (Figure $4 \mathrm{~d}$ ). Histological scoring shows that phenanthrene exposure resulted in a significantly increased dilation of the acinal wall (one-way ANOVA, $p<0.001$, Holm-Sidak, Figure $3 \mathrm{~d}$ ). In solventtreated samples dilation of the acinal wall occurred slightly more often than in control samples. 
333 It is well known that PAHs and oil elicit histopathological effects on gonads in marine

invertebrates such as degeneration of germ cells and gonadal follicles, atrophy of gonadal tissue as well as inflammatory reactions (Lowe and Pipe, 1986; Berthou et al., 1987; Cajaraville et al., 1990; Tay et al., 2003; Aarab et al., 2004; Ortiz-Zarragoitia and Cajaraville, 2006). Indeed, the mentioned studies deal solely with molluscan species. To our knowledge the present study is the first one investigating the effects of a PAH on sea urchin gonads.

Psammechinus miliaris showed severe ovarian lesions after exposure to the sublethal concentration of phenanthrene. The gonad size and the gonad index of the sea urchins were significantly reduced indicating tissue atrophy. Similarly, Berthou et al. (1987) observed atrophy of the gonad concomitantly with a decrease in the gonad index in oysters in areas polluted by the Amoco Cadiz oil spill.

Strikingly, in $P$. miliaris exposed to phenanthrene the acinal structure was disorganized which was mainly due to aggregates of degenerating oocytes. This disorganisation makes a proper oogenesis unlikely since the migration of maturing oocytes towards the acinal lumen is hampered. Generally, degeneration of ovarian follicles is described as follicular atresia and stress such as exposure to xenobiotics appears to increase the incidence of atretic follicles (Dietrich et al., in press). Degenerating follicles were also observed in Mytilus edulis exposed 352 to a mixture of North Sea oil, alkylphenols and PAHs. Exposure to $0.5 \mathrm{ppm}$ North Sea oil 353 alone, however, increased the size and number of ovarian follicles in the mussels (Aarab et 354 al., 2004). In the present study, a few degenerating acini were also found in control animals which may resorb malfunctional oocytes to preserve normal gonadal function as known from atretic follicles in female fish (Dietrich et al., in press).

Furthermore, phenanthrene exposure significantly increased degeneration of previtellogenic oocytes in the ovary of $P$. miliaris. PAHs and oil are known to increase the prevalence of oocyte degeneration or oocyte atresia in molluscs: Ortiz-Zarragoitia and Cajaraville (2006) 
361 found a higher volume density of atretic oocytes in mussels (Mytilus edulis) exposed to 0.5 ppm North Sea oil and to a mixture of North Sea oil $(0.5 \mathrm{ppm})$, alkylphenols $(0.1 \mathrm{ppm})$ and extra polycyclic aromatic hydrocarbons $(0.1 \mathrm{ppm})$ for three weeks. In $M$. edulis experimentally exposed to low (28 ppb) and high (128 ppb) doses of diesel oil for three months the volume of atretic oocytes was also significantly increased (Lowe and Pipe, 1986). In the Baltic clam (Macoma balthica) necrosis of primary and secondary oocytes as well as ripe ova was reported after 28 days exposure to sediments highly contaminated with PAHs, polychlorinated biphenyls (PCBs), and heavy metals (Tay et al., 2003). Astonishingly, in clams exposed to sediment with a very high concentration of PAHs no ovarian lesions were detected (Tay et al., 2003).

In the present study, previtellogenic oocytes showed a reduction in size and vitellogenic oocytes showed a reduction in numbers in $P$. miliaris after maternal exposure to phenanthrene. It is unclear whether inhibition of oocyte growth and maturation by phenanthrene exposure is the underlying mechanism of these findings. The low number of vitellogenic oocytes may also be a result of spawning induced by exposure to phenanthrene since spawning is known to be accelerated in mussels (Mytilus galloprovincialis) exposed to high doses of oil (Cajaraville et al., 1992). However, no increased spawning events in the phenanthrene-treated group were observed during the experiment in comparison to controls. 380 Regarding the previtellogenic oocytes, it could be speculated that their small size may, next 381 to an inhibition of growth, result from degeneration and their resorption by NPs. Studying the 382 effects of phenanthrene exposure at different times during oogenesis may clarify whether phenanthrene exposure inhibits growth and maturation of oocytes. Interestingly, in contrast to the severe alterations of previtellogenic oocytes, we found no adverse effects of phenanthrene on vitellogenic oocytes and mature eggs. It has to be considered that later developmental stages of oocytes may be better protected against pollutant stress: Eggs of sea urchins and sea stars are known to express low levels of efflux transporter genes (Hamdoun et al., 2004; Roepke et al., 2006). In sea stars efflux transporter activities are 
known to increase during oocyte maturation (Roepke et al., 2006). Moreover, younger oocytes may be more sensitive to pollutants due to their higher surface to volume ratio. Further, it has to be considered that release of affected gametes may result in underestimating the adverse effects of phenanthrene on oocytes and eggs in $P$. miliaris.

After exposure to phenanthrene we observed elevated but not statistically significant increased deposition of lipofuscin in the ovaries of $P$. miliaris. In several studies, lipofuscin accumulation in fish liver and mussel digestive gland is associated with oxidative stress caused by pollution with oil and PAHs (Krishnakumar et al., 1994, 1997; Au et al. 1999; Au, 2004). In the reproductive tissue of the sea urchin Strongylocentrotus intermedius inhabiting polluted areas in the Sea of Japan, lipofuscin accumulation was related to contamination with heavy metals (Vashchenko and Zhadan, 1993; Vaschchenko et al., 2001; Vashchenko et al., 2001). As demonstrated in the present study, Vaschenko et al. (2001) and Vashchenko et al. (2001) also found lipofuscin deposition in NPs and in the hemal sinuses of the acinal walls. However, in contrast to our findings, the authors further identified lipofuscin accumulation in germ cells of S. intermedius (Vaschenko et al., 2001; Vashchenko et al., 2001). Indeed, preliminary studies with a wild population of $P$. miliaris indicate that lipofuscin accumulation in the reproductive tissue is dependent on the reproductive stage and the sex of the organism (Schäfer \& Köhler, unpublished). It has to be further investigated whether lipopigment deposition in reproductive tissue of sea urchins is a useful biomarker for pollutant stress.

410 The NPs showed increased phagocytic activity in the phenanthrene-treated animals. This 411 may indicate early phagocytosis and resorption of gonadal and oocyte material as a result of improper ovarian and gamete development. Gamete resorption is a natural phenomenon in 413 echinoderms that occurs in both sexes at the end of the spawning season (Kalachev and 414 Reunov, 2005) but it is also described in the sea urchin Strongylocentrotus intermedius from 415 polluted areas in the Sea of Japan (Vashchenko and Zhadan, 1993). The PAH-induced 
416 gamete resorption in the gonads is also reported in the prosobranch Littorina littorea after

short-term exposure to high concentrations of the PAH 1-napthol (Cajaraville et al., 1990).

The acinal wall of Psammechinus miliaris was severely affected by phenanthrene exposure showing dilation of the epithelial layers and increased formation of collagen. Further, augmentation of basophilic structures occurred which can not be identified so far. The thickness of the gonadal wall of the sea urchin Arbacia punctulata is reported to change during the year (Palmer Wilson, 1940). Increased deposition of collagen in conjunction with a thickened appearance of connective tissue, however, is generally known as fibrosis (Dietrich et al., in press). In reproductive tissue of invertebrates fibrosis is described from gonadal neoplasms in mussels (Peters et al., 1994). And in the prosobranch Littorina littorea fibrosis was shown after short-term exposure to high concentrations of the PAH 1-napthol (Cajaraville et al., 1990). When immune cells are present simultaneously fibrosis is assumed to be a scarring process. In a few studies infiltration with immune cells have been described in invertebrates after exposure to oil and PAHs (Berthou et al., 1987; Cajaraville et al., 1990; Cajaraville et al., 1992). Indeed, a clear diagnosis of immune reactions in the present study was difficult since, to our knowledge, there is no detailed histological description of immune cells of sea urchins, the coelomocytes, in situ. Furthermore, coelomocytes had a similar appearance as epithelial cells of the acinal wall in Psammechinus miliaris.

The concentration of phenanthrene used in the present study is, in general, higher than levels of PAHs found in the marine environment: In seawater around England and Wales background concentrations of PAHs range from none detected to $10.7 \mu \mathrm{g} \mathrm{L}^{-1}$ total PAHs (Law et al., 1997). 'Safe' levels of phenanthrene for aquatic organisms set by several countries are equal or below $4.6 \mu \mathrm{g} \mathrm{L}^{-1}$ (Law et al., 1997). After the Exxon Valdez oil spill in Prince William Sound in the Northern Gulf of Alaska in 1989 where around 37000 metric tons of crude oil were released an average of $0.4 \mu \mathrm{g} \mathrm{L}^{-1}$ total petroleum hydrocarbon were measured at polluted sites (Boehm et al., 1990). However, after the Hebei Spirit incident at 
444 the West coast of Korea in July 2007 up to $17 \mathrm{mg} \mathrm{L}^{-1}$ and an average of $626 \mathrm{\mu g} \mathrm{L}^{-1}$ total

petroleum hydrocarbons were measured (Shim, 2008). However, direct comparison of concentrations used in the present study and levels of PAHs or phenanthrene found in the marine environment in general or at point sources are difficult since combinations of PAHs may have different effects than single chemicals (Hylland, 2006). Contamination of sea urchin habitats with PAHs e.g. by oil spills or release of oil from oil platforms may have severe impacts on sea urchin populations. Daan \& Mulder (1996), for example, have shown that the abundance of the echinoidea Echinocardium cordatum was reduced close to a drilling station in the North Sea where oil-based drilling muds had been used. Following the Torrey Canyon oil spill in 1967 large numbers of dead Psammechinus miliaris where found in the vincinity which may be attributed to the hydrocarbon exposure and the heavy spraying of hydrocarbon based dispersants in that area (Smith, 1968).

In summary, 20 days exposure towards sublethal concentrations of phenanthrene resulted in severe ovarian lesions of Psammechinus miliaris which make a proper oogenesis unlikely. Strikingly, the acinal structure was disorganized which may be analogous to follicular atresia in other invertebrates and fish. Previtellogenic oocytes were severely affected while there were no obvious effects on vitellogenic oocytes and mature ova. For future studies, the usefulness of lipofuscin accumulation in gonads of sea urchins as a biomarker needs to be further investigated. Moreover, a detailed description of coelomocytes in situ is necessary to clearly identify immune reactions in sea urchin tissues and to compare histopathological effects of pollutants with studies on other invertebrate species.

\section{Acknowledgements}

This study was financed by the Alfred Wegener Institute for Polar and Marine Research within the Helmholtz Association. It is part of a PhD study conducted at the Jacobs University Bremen. The authors thank B. Hussel and the staff of the FS Mya for collecting the sea 
471 urchins. We are grateful to two anonymous reviewers for providing helpful comments on the

manuscript.

\section{Literature}

Aarab, N., Minier, C., Lemaire, S., Unruh, E., Hansen, P.D., Larsen, B.K., Andersen, O.K., Narbonne, J.F., 2004. Biochemical and histological responses in mussel (Mytilus edulis) exposed to North Sea oil and to a mixture of North Sea oil and alkylphenols. Marine Environmental Research 58, 437-441.

Au, D.W.T., 2004. The application of histo-cytopathological biomarkers in marine pollution monitoring: a review. Marine Pollution Bulletin 48, 817-834.

Au, D.W.T., Lee, C.Y., Chan, K.L., Wu, R.S.S., 2001a. Reproductive impairment of sea urchins upon chronic exposure to cadmium. Part I: Effects on gamete quality. Environmental Pollution 111, 1-9.

Au, D.W.T., Reunov, A.A., Wu, R.S.S., 2001b. Reproductive impairment of sea urchin upon chronic exposure to cadmium. Part II: Effects on sperm development. Environmental Pollution 111, 11-20.

Au, D.W.T., Wu, R.S.S., Zhou, B.S., Lam, P.K.S., 1999. Relationship between ultrastructural changes and EROD activities in liver of fish exposed to Benzo[a]pyrene. Environmental Pollution 104, 235-247.

Au, D.W.T., Yurchenko, O.V., Reunov, A.A., 2003. Sublethal effects of phenol on spermatogenesis in sea urchins (Anthocidaris crassispina). Environmental Research 93, 9298.

Berthou, F., Balouet, G., Bodennec, G., Marchand, M., 1987. The occurrence of hydrocarbons and histopathological abnormalities in oysters for 7 Years Following the Wreck of the Amoco-Cadiz in Brittany (France). Marine Environmental Research 23, 103-133.

Blazer, V.S., 2002. Histopathological assessment of gonadal tissue in wild fishes. Fish Physiology and Biochemistry 26, 85-101.

Boehm, P.D., Neff, J.M., Page, D.S., 2007. Assessment of polycyclic aromatic hydrocarbon exposure in the waters of Prince William Sound after the Exxon Valdez oil spill: 1989-2005. Marine Pollution Bulletin 54, 339-367.

Boschma, H., de Beaufort, L.F., van Oort, E.D., Redeke, H.C., Roepke, W., 1932. Aflevering VI: Echinodermata. A. W. Sijthoff's Uitgeversmij N.V., Leiden.

Byrne, M., 1990. Annual reproductive cycles of the commercial sea urchin Paracentrotus lividus from an exposed intertidal and a sheltered subtidal habitat on the west coast of Ireland. Marine Biology 104, 275-289.

Cajaraville, M.P., Marigómez, J.A., Angulo, E., 1990. Short-term toxic effects of 1-naphthol on the digestive gland-gonad complex of the marine prosobranch Littorina littorea $(L)$ : A light microscopic study. Archives of Environmental Contamination and Toxicology 19, 17-24.

Cajaraville, M.P., Marigómez, J.A., Angulo, E., 1992a. Comparative effects of the water accommodated fraction of three oils on mussels - 1. Survival, growth and gonad 
development. Comparative Biochemistry and Physiology Part C: Comparative Pharmacology $102,103-112$.

Cajaraville, M.P., Marigomez, J.A., Diez, G., Angulo, E., 1992b. Comparative Effects of the Water Accommodated Fraction of Three Oils on Mussels - 2. Quantitative Alterations in the Structure of the Digestive Tubules. Comparative Biochemistry and Physiology Part C: Comparative Pharmacology 102, 113-123.

Caldwell, G.S., Bentley, M.G., Olive, P.J.W., 2004. First evidence of sperm motility inhibition by the diatom aldehyde 2E, 4E-decadienal. Marine Ecology Progress Series 273, 97-108.

Caldwell, G.S., Olive, P.J.W., Bentley, M.G., 2002. Inhibition of embryonic development and fertilization in broadcast spawning marine invertebrates by water soluble diatom extracts and the diatom toxin 2-trans,4-trans decadienal. Aquatic Toxicology 60, 123-137.

Campbell, A.C., 1977. The Hamlyn Guide to the seashore and shallow seas of Britain \& Europe. Hamlyn Publishing Group, London, 320 pp.

Cerri, P.S., Sasso-Cerri, E., 2003. Staining methods applied to glycol methacrylate embedded tissue sections. Micron 34, 365-372.

Chatlynne, L.G., 1969. A histochemical study of oogenesis in the sea urchin Strongylocentrotus purpuratus. Biological Bulletin 136, 167-184.

Daan, R. \& Mulder, M. 1996. On the short-term and long-term impact of drilling activites in the Dutch sector of the North Sea. ICES Journal of Marine Science 53: 1036-1044.

Dietrich, D.R., Krieger, H.O., Rumpf, S., in press. Histological Analysis of endocrine disruptive effects in small laboratory fish. Wiley \& Sons Inc.

Greenwood, P.J., 1980. Possible uses of the developmental embryology of the sea urchin Parechinus angulosus for pollution monitoring in the nearshore marine environment. $\mathrm{PhD}$ thesis, University of Cape Town, $334 \mathrm{pp}$.

Hamdoun, A.M., Cherr, G.N., Roepke, T.A., Epel, D., 2004. Activation of multidrug efflux transporter activity at fertilization in sea urchin embryos (Strongylocentrotus purpuratus). Developmental Biology 276, 452-462.

Haschek, W.M., Rousseaux, C.G., 1998. Fundamentals of Toxicologic Pathology. Academic Press, San Diego. 563 pp.

Hose, J.E., 1985. Potential uses of sea urchin embryos for identifying toxic chemicals: description of a bioassay incorporating cytologic, cytogenetic and embryologic endpoints. Journal of Applied Toxicology 5, 245-254.

Hylland, K. 2006. Polycyclic aromatic hydrocarbon (PAH) ecotoxicology in marine ecosystems. Journal of Toxicology and Environmental Health A 59, 109-123.

Kalachev, A.V., Reunov, A.A., 2005. Resorption of Gametes in the Testes of the Sea Star Asterina pectinifera (Mueller et Troschel, 1842). Russian Journal of Marine Biology 31, 119123.

Kelly, M.S., 2000. The reproductive cycle of the sea urchin Psammechinus miliaris (Echinodermata: Echinoidea) in a Scottish sea loch. Journal of the Marine Biological Association of the UK 80, 909-919. 
Kelly, M.S., Brodie, C.C., McKenzie, J.D., 1998. Somatic and gonadal growth of the sea urchin Psammechinus miliaris (Gmelin) maintained in poyculture with the Atlantic salmon. Journal of Shellfish Research 17, 1557-1562.

Klöckner, K., Rosenthal, H., Willführ, J., 1985. Invertebrate bioassays with North Sea water samples. I. Structural effects on embryos and larvae of serpulids, oysters and sea urchins. Helgoland Marine Research 39, 1-19.

Kobayashi, N., 1980. Comparative sensitivity of various developmental stages of sea urchins to some chemicals. Marine Biology 58, 163-171.

Köhler, A., 2004. The gender-specific risk to liver toxicity and cancer of flounder (Platichthys flesus (L.)) at the German Wadden Sea coast. Aquatic Toxicology 70, 257-276.

Krishnakumar, P.K., Casillas, E., Varanasi, U., 1994. Effect of environmental contaminants on the health of Mytilus edulis from Puget Sound, Washington, USA. 1. Cytochemical measures of lysosomal responses in the digestive cells using automatic image analysis. Marine Ecology Progress Series 106, 249-261.

Krishnakumar, P.K., Casillas, E., Varanasi, U., 1997. Cytochemical responses in the digestive tissue of Mytilus edulis complex exposed to microencapsulated PAHs or PCBs. Comparative Biochemistry and Physiology Part C: Pharmacology, Toxicology and Endocrinology 118, 11-18.

Law, R.J., Dawes, V.J., Woodhead, R.J., Matthiessen, P. 1997. Polycyclic aromatic hydrocarbons (PAH) in seawater around England and Wales. Marine Pollution Bulletin 34(5), 306-322.

Lendrum, A.C., Slidders, W., Fraser, D.S., 1972. Renal hyalin - Study of amyloidosis and diabetic fibrinous vasculosis with new staining methods. Journal of Clinical Pathology 25, 373.

Lowe, D.M., Pipe, R.K., 1986. Hydrocarbon exposure in mussels - a quantitative study of the responses in the reproductive and nutrient storage cell systems. Aquatic Toxicology 8, 265272.

Ortiz-Zarragoitia, M., Cajaraville, M., 2006. Biomarkers of exposure and reproduction-related effects in mussels exposed to endocrine disruptors. Archives of Environmental Contamination and Toxicology 50, 361-369.

Palmer Wilson, L., 1940. Histology of the gonad wall of Arbacia punctulata. Journal of Morphology 66, 463-479.

Pearse, A.G.E. 1985. Histochemistry: Theoretical and Applied, Vol. 2, Analytical Technology, 4th edition, Churchill Livingstone, Edinburgh, London, Melbourne and New York, p. 748.

Peters, E.C., Yevich, P.P., Harshbarger, J.C., Zaroogian, G.E., 1994. Comparative histopathology of gonadal neoplasms in marine bivalve mollusks. Diseases of Aquatic Organisms 20, 59-76.

Pillai, M.C., Vines, C.A., Wikramanayake, A.H., Cherr, G.N., 2003. Polycyclic aromatic hydrocarbons disrupt axial development in sea urchin embryos through a [beta]-catenin dependent pathway. Toxicology 186, 93-108. 
633

1634

2635

3636

4637

5638

6
7 639

7640

8641

10642

11643

12644

13645

14646

15647

16648

17648

18650

20651

21652

22653

23654

24655

25656

$26 \quad 657$

28658

29659

30660

31661

32662

33663

$\begin{array}{ll}34 & 664\end{array}$

35665

$36 \quad 665$

$\begin{array}{ll}37 & 666 \\ 38 & 667\end{array}$

39668

40669

41670

42671

43672

44673

45674

47675

48676

49677

50678

51679

52680

53681

54682

$\begin{array}{ll}55 & 682\end{array}$

57684

58685

59686

60

61

62

63

64

65

Roepke, T.A., Hamdoun, A.M., Cherr, G.N., 2006. Increase in multidrug transport activity is associated with oocyte maturation in sea stars. Development Growth and Differentiation 48, 559-573.

Sakamaki, K., 2003. Physiological and pathological cell deaths in the reproductive organs. Cell Structure and Function 28, 31-40.

Scheibling, R., 1986. Increased macroalgal abundance following mass mortalities of sea urchins (Strongylocentrotus droebachiensis) along the Atlantic coast of Nova-Scotia. Oecologia 68, 186-198.

Schäfer, S. \& Köhler, A., unpublished. Seasonal alterations in reproductive tissue of the sea urchin Psammechinus miliaris in the northern Wadden Sea.

Shim, W.K. 2008. Environmental impact assessment following the Hebei Spirit inicident. KORDI-NOAA workshop. Korean Ocean Research and Development Institute (KORDI). Ansan. Korea. $13^{\text {th }}$ of May 2008

Smith, J.E., 1968. 'Torrey Canyon'. Pollution and marine life. A report by the Plymouth Laboratory of the Marine Biological Association of the United Kingdom. Cambridge. Cambridge University Press.

Steevens, J.A., Slattery, M., Schlenk, D., Aryl, A., Benson, W.H., 1999. Effects of ultraviolet$B$ light and polyaromatic hydrocarbon exposure on sea urchin development and bacterial bioluminescence. Marine Environmental Research 48, 439-457.

Steneck, R.S., Graham, M.H., Bourque, B.J., Corbett, D., Erlandson, J.M., Estes, J.A., Tegner, M.J., 2002. Kelp forest ecosystems: biodiversity, stability, resilience and future. Environmental Conservation 29, 436-459.

Tay, K.L., Teh, S.J., Doe, K., Lee, K., Jackman, P., 2003. Histopathologic and histochemical biomarker responses of Baltic clam, Macoma balthica, to contaminated Sydney Harbour sediment, Nova Scotia, Canada. Environmental Health Perspectives 111, 273-280.

Terman, A., Brunk, U.T., 2004. Lipofuscin. International Journal of Biochemistry \& Cell Biology 36, 1400-1404.

U.S. EPA, 1993. Sea urchin, Arbacia punctulata, fertilization test, Method 1008.0. In: Shortterm methods for estimating the chronic toxicity of effluents and receiving waters to marine and estuarine organisms, 2nd ed. US Environmental Protection Agency, report EPA/600/491/003, July 1994, Cincinnati, OH, pp 300-340

Vaschenko, M.A., Zhadan, P.M., Latypova, E.V., 2001. Long-term changes in the state of gonads in sea urchins Strongylocentrotus intermedius from Amur Bay, the Sea of Japan. Russian Journal of Ecology 32, 358-364.

Vashchenko, M.A., Zhadan, P.M., 1993. Ecological assessment of marine environment using two sea urchin tests: disturbance of reproduction and sediment embryotoxicity. Science of the Total Environment 134, 1235-1245.

Vashchenko, M.A., Zhadan, P.M., Latypova, E.V., 2001. Long-term changes in the gonad condition of the sea urchin Strongylocentrotus intermedius from Alekseev Bight (Amurskii Bay) under polluted conditions. Russian Journal of Marine Biology 27, 49-53. 
687 Walker, C.W., McGinn, N.A., Harrington, L.M., Lesser, M.P., 1998. New perspectives on sea 1688 urchin gametogenesis and their relevance to aquaculture. Journal of Shellfish Research 17, 2689 1507-1514.

3690

4691

Westheide, W., Rieger, R., 1996. Spezielle Zoologie. Erster Teil: Einzeller \& Wirbellose Tiere 5692

6693

Gustav Fischer Verlag, Stuttgart, Jena, New York. 
695

1696

2697

3698

4699

5700

6701

7702

8703

10704

11

12

13

14

15

16

17

18

19

20

21

22

23

24

25

26

27

28

29

30

31

32

33

34

35

36

37

38

39

40

41

42

43

44

45

46

47

48

49

50

51

52

53

54

55

56

57

58

59

60

61

62

63

64

65

\section{Tables \& Figures}

\subsection{Table}

Table 1

Growth parameters of Psammechinus miliaris in the different treatments. Standard deviations are in parentheses. Different letters in the same row indicate statistical significant differences between the treatments (control at day $0: n=24$, all other treatments: $n=30$, one-way ANOVA, Tukey HSD, $\mathrm{p}<0.05)$. 
705

1706

2707

3708

4709

5710

6711

7711

8712

9713

10714

11715

12716

13717

14718

15719

16720

17721

19722

20723

21724

22725

23726

24727

25728

26729

28730

29731

30732

31733

32734

33735

34736

35737

36738

$\begin{array}{ll}37 & 738 \\ 38 & 739\end{array}$

39740

40741

41742

42743

43744

44745

45746

47747

48748

49749

50750

51751

52752

53753

54754

55755

57756

58757

59758

60759

61760

\subsection{Figures}

Figure 1

Ovary sections of control animals of Psammechinus miliaris stained with Alcian Blue/PAS a) Typical acinus of an ovary surrounded by a thin acinal wall. Early oocyte stages such as previtellogenic oocytes are found close to the acinal wall, whereas later oocyte stages such as vitellogenic oocytes are found in the lumen of the acinus. Note the empty spaces between the oocytes which result from spawning of oocytes. (bar $=100 \mu \mathrm{m}) \mathrm{b}$ ) Previtellogenic oocyte of a control animal with a large germinal vesicle containing a big nucleolus (bar $=10 \mu \mathrm{m}$ ), c) vitellogenic oocyte showing PAS+ granules in the cytoplasm (bar $=20 \mu \mathrm{m}$ ), d) mature ova showing PAS+ granules in the cytoplasm and missing a germinal vesicle (bar $20 \mu \mathrm{m}$ ). AW = acinal wall, $\mathrm{GV}=$ germinal vesicle, $\mathrm{N}=$ nucleolus, $\mathrm{NP}=$ nutritive phagocytes, $\mathrm{PO}=$ previtellogenic oocyte, $\mathrm{VO}=$ vitellogenic oocyte.

\section{Figure 2}

a) - c) Ovary sections of phenanthrene-exposed Psammechinus miliaris stained with Alcian Blue/PAS a) acinus showing severe disorganisation of the acinal structure with an aggregate of degenerating oocytes in the lower right and several small degenerating oocytes. Note the dilation of the acinal wall. (bar $=100 \mu \mathrm{m}$ ) b) aggregate of degenerating oocytes (bar $=20$ $\mu \mathrm{m}) \mathrm{c}$ ) oocytes showing signs of degeneration with vacuolisation of the cytoplasm, cell lysis, infoldings of the nuclear membrane and disruption of the nuclear membrane (bar $=10 \mu \mathrm{m})$. $\mathrm{AL}=$ acinal lumen, $\mathrm{AW}=$ acinal wall, $\mathrm{D}=$ disruption of the nuclear membrane, $\mathrm{DO}=$ degenerating oocyte, GV = germinal vesicle, IF = infoldings of the nuclear membrane, Ly = cell lysis, $\mathrm{N}=$ nucleolus, $\mathrm{NP}=$ nutritive phagocytes, $\mathrm{PO}=$ previtellogenic oocyte, $\mathrm{VC}=$ vacuolisation of the cytoplasm.

\section{Figure 3}

Histopathologic alterations depicted as bar charts with the mean values and standard deviations. Different letter indicate significant differences $(p<0.05)$. a) areal density [\%] of aggregates of degenerating oocytes (one-way ANOVA, Holm-Sidak), b) areal density [\%] of lipofuscin accumulation in the ovaries (one-way ANOVA), c) percentage of degenerating previtellogenic oocytes (Kruskal-Wallis, Dunn's test), d) dilation of the acinal wall (one-way ANOVA, Holm-Sidak).

\section{Figure 4}

a) - b) Ovary section of a phenanthrene-exposed individual stained with the Schmorl's method, a) overview taken at lower magnification showing high deposition of lipofuscin in the acini. Note the lipofuscin accumulation outside of the acini in conjunction with coelomocytes (bar $=100 \mu \mathrm{m}$ ), b) detail of a) with lipofuscin granules (arrows) (bar $=10 \mu \mathrm{m}), c)-\mathrm{d}$ ) Ovary sections of Psammechinus miliaris stained with Picrosirius, c) Thin acinal wall of a control animal with the inner and outer epithelial layers (bar $=20 \mu \mathrm{m})$, d) Acinal wall of a phenanthrene-exposed animal showing dilation of the inner and outer epithelial layers concomitant with increased deposition of collagen and unknown basophilic material. Note the small cells at the outer epithelial layer which may be attacking coelomocytes (bar $=20 \mu \mathrm{m}$ ), e) Acinal wall of a phenanthrene-exposed animal showing dilation of the inner and outer epithelial layers $(\mathrm{bar}=20 \mu \mathrm{m})$. AW $=$ acinal wall, bas $+=$ basophilic material, $\mathrm{C}=$ collagen, $\mathrm{CA}=$ coelomocyte aggregate, $\mathrm{CO}=$ coelomocytes $(?), \mathrm{DO}=$ degenerating oocyte, $\mathrm{GV}=$ germinal vesicle, IL = inner epithelial layer, $\mathrm{N}=$ nucleolus, $\mathrm{NP}=$ nutritive phagocytes, $\mathrm{OL}=$ outer epithelial layer, $\mathrm{PO}=$ previtellogenic oocyte. 


\begin{tabular}{|c|c|c|c|c|}
\hline \multirow[b]{3}{*}{ parameter / treatment } & \multicolumn{4}{|c|}{ days } \\
\hline & \multirow{2}{*}{$\begin{array}{r}0 \\
\text { control }\end{array}$} & \multicolumn{3}{|c|}{20} \\
\hline & & control & $\begin{array}{l}\text { solvent } \\
\text { control }\end{array}$ & phenanthrene \\
\hline $\begin{array}{l}\text { mean vertical test } \\
\text { diameter }[\mathrm{mm}]\end{array}$ & $17.5^{\mathrm{a}}(1.7)$ & $17.4^{\mathrm{a}}(1.9)$ & $17.6^{\mathrm{a}}(2.5)$ & $17.4^{\mathrm{a}}(2.8)$ \\
\hline $\begin{array}{l}\text { mean horizontal test } \\
\text { diameter [mm] }\end{array}$ & $30.9^{\mathrm{a}}(3.2)$ & $30.4^{\mathrm{a}}(3.3)$ & $30.6^{\mathrm{a}}(3.9)$ & $31.8^{\mathrm{a}}(3.5)$ \\
\hline $\begin{array}{l}\text { mean somatic weight } \\
\text { [a] }\end{array}$ & $13.0^{\mathrm{a}}(3.6)$ & $12.4^{\mathrm{a}}(2.9)$ & $12.7^{\mathrm{a}}(3.9)$ & $13.5^{\mathrm{a}}(3.8)$ \\
\hline $\begin{array}{l}\text { mean gonad weight } \\
\text { [mg] }\end{array}$ & $723^{a}(445)$ & $712^{\mathrm{a}}(384)$ & $582^{\mathrm{a}}(493)$ & $390^{\mathrm{b}}(257)$ \\
\hline gonad index [\%] & $5.4^{\mathrm{a}}(2.2)$ & $5.8^{\mathrm{a}}(2.2)$ & $4.5^{\mathrm{a}}(2.2)$ & $2.9^{b}(1.9)$ \\
\hline
\end{tabular}



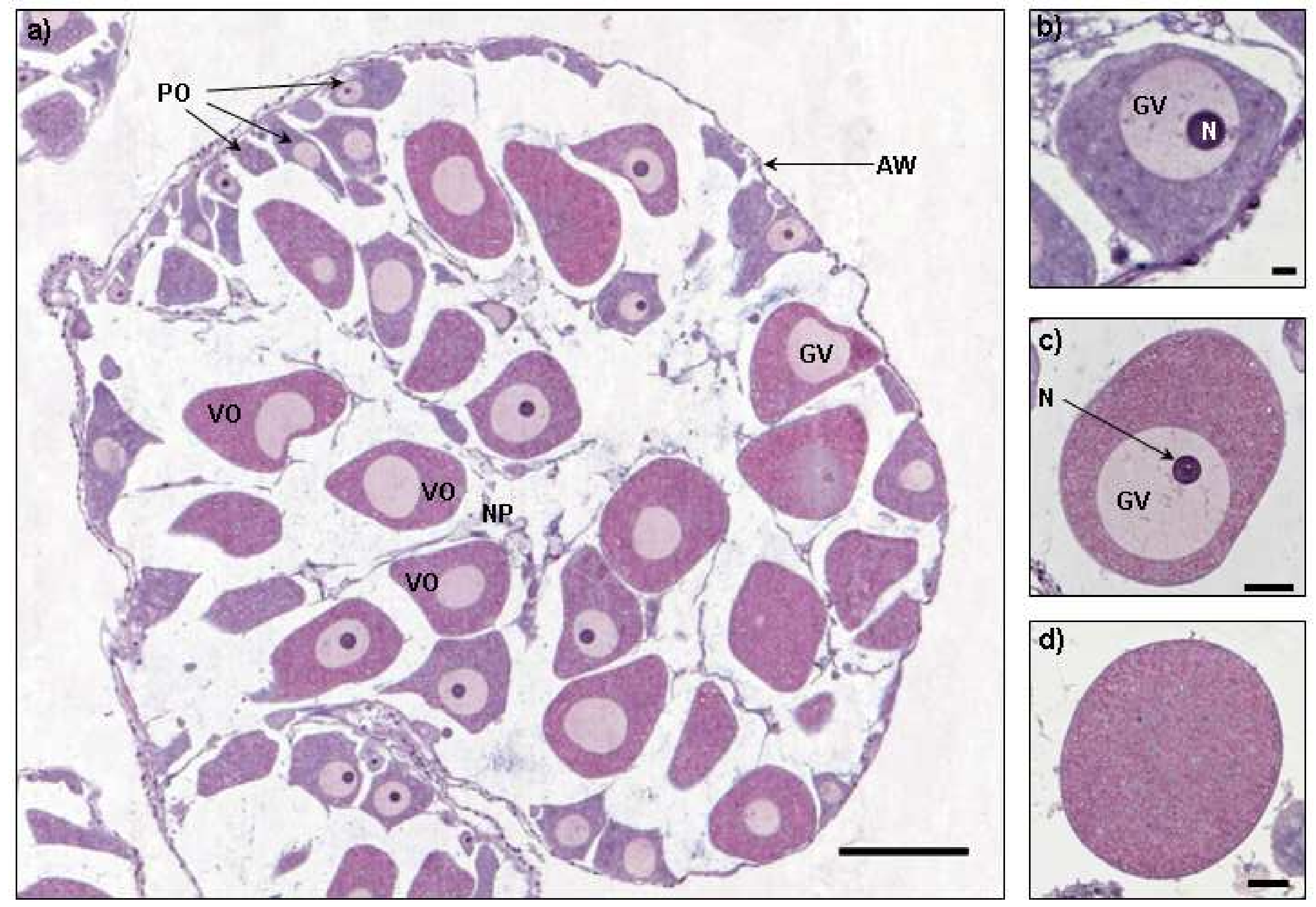

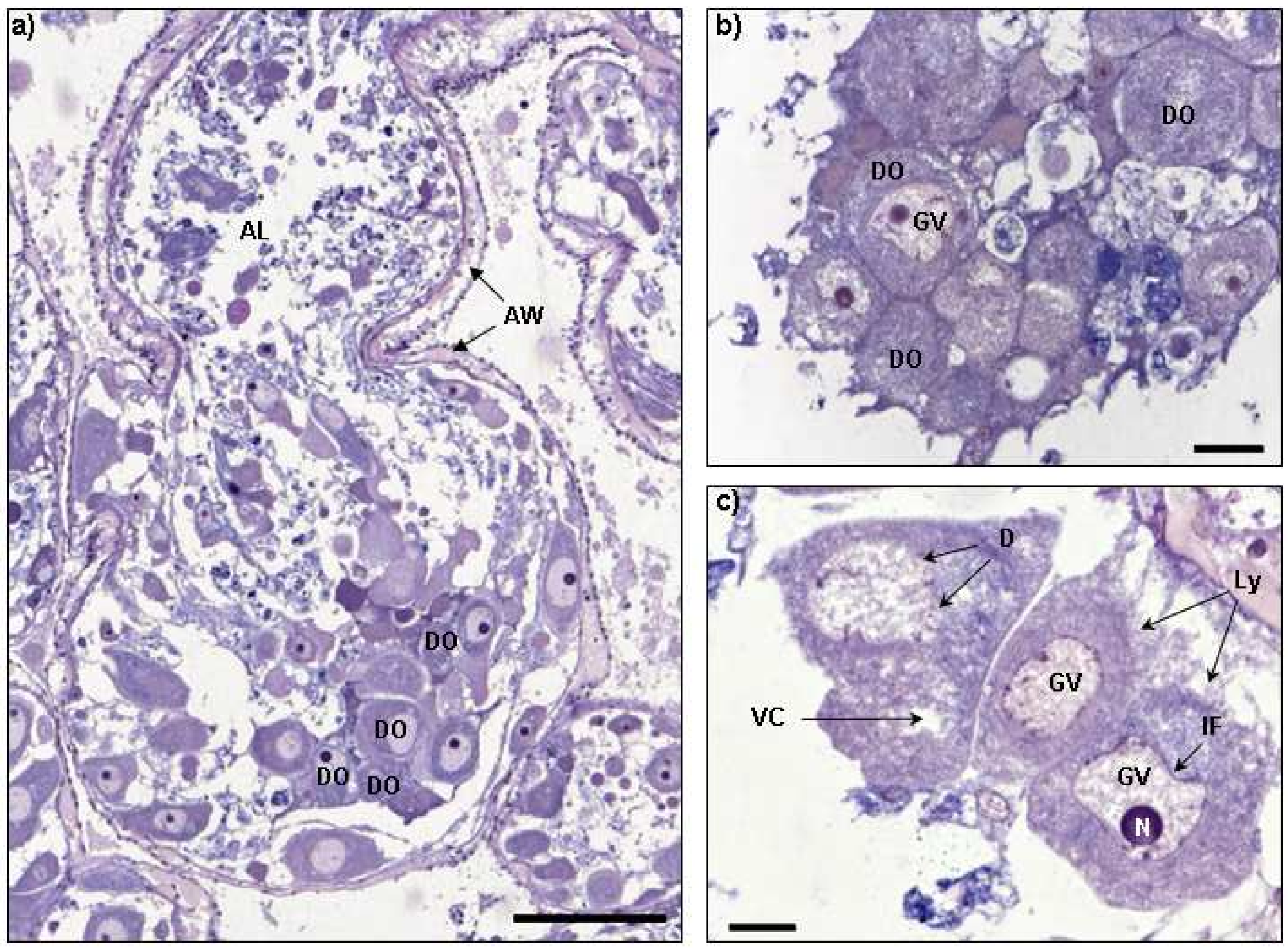
a)

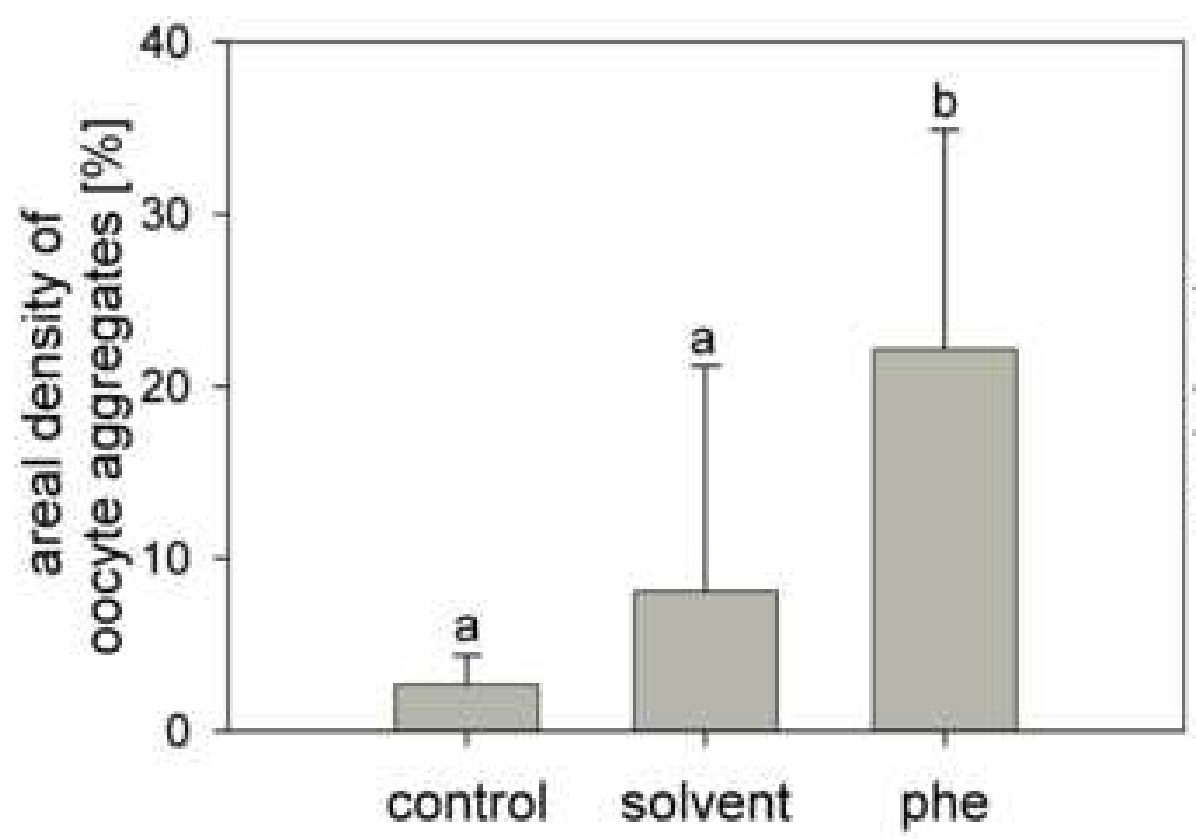

c)

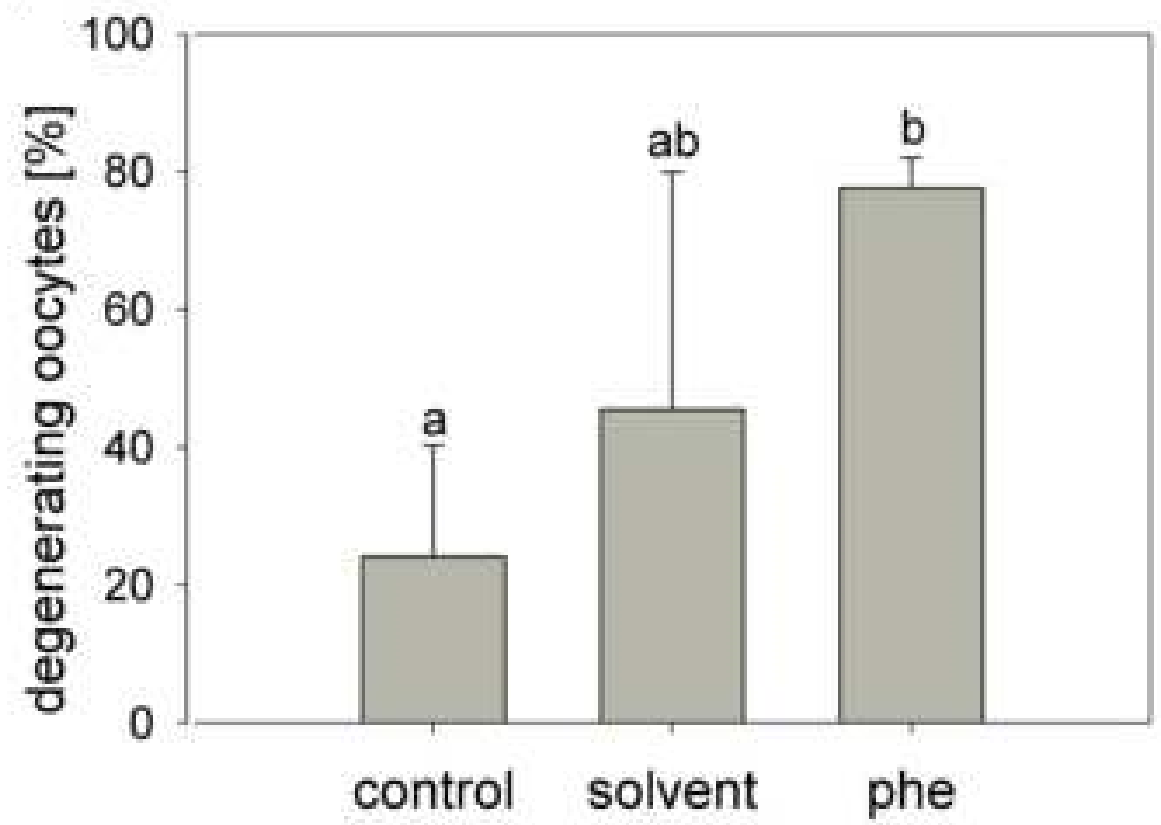

b)

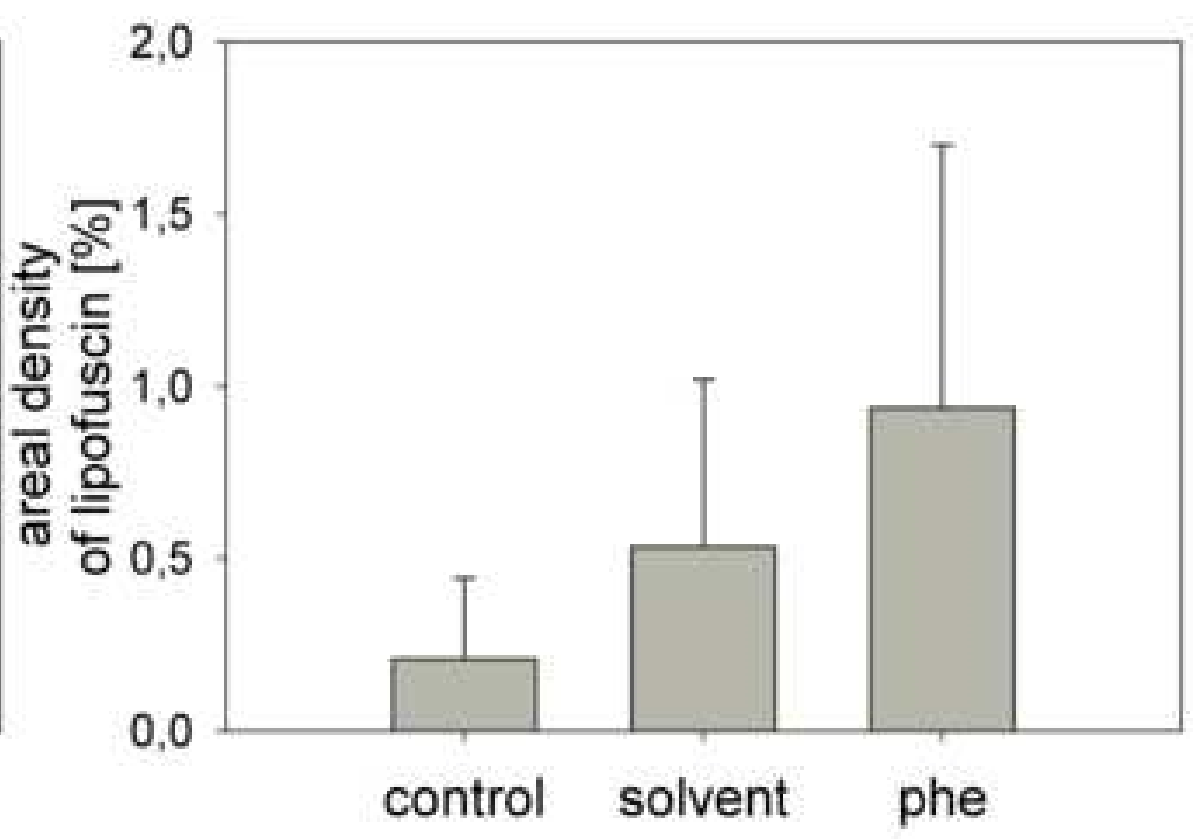

d)

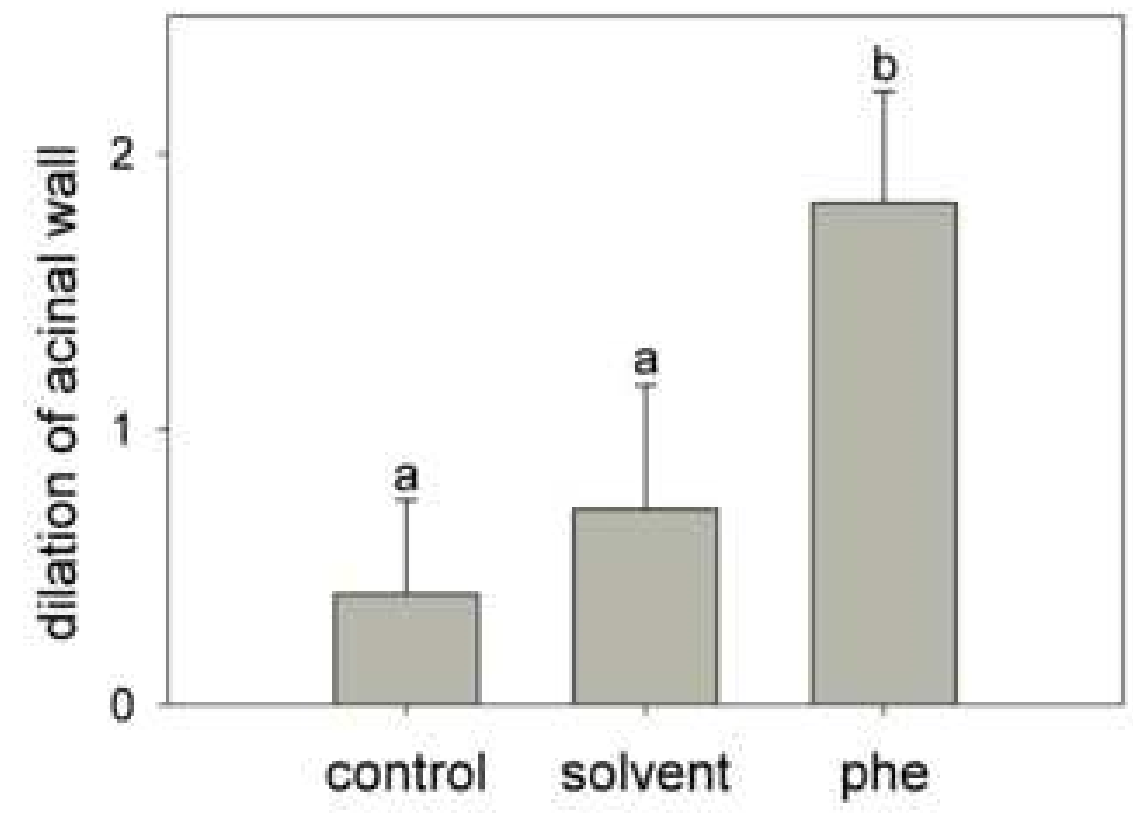



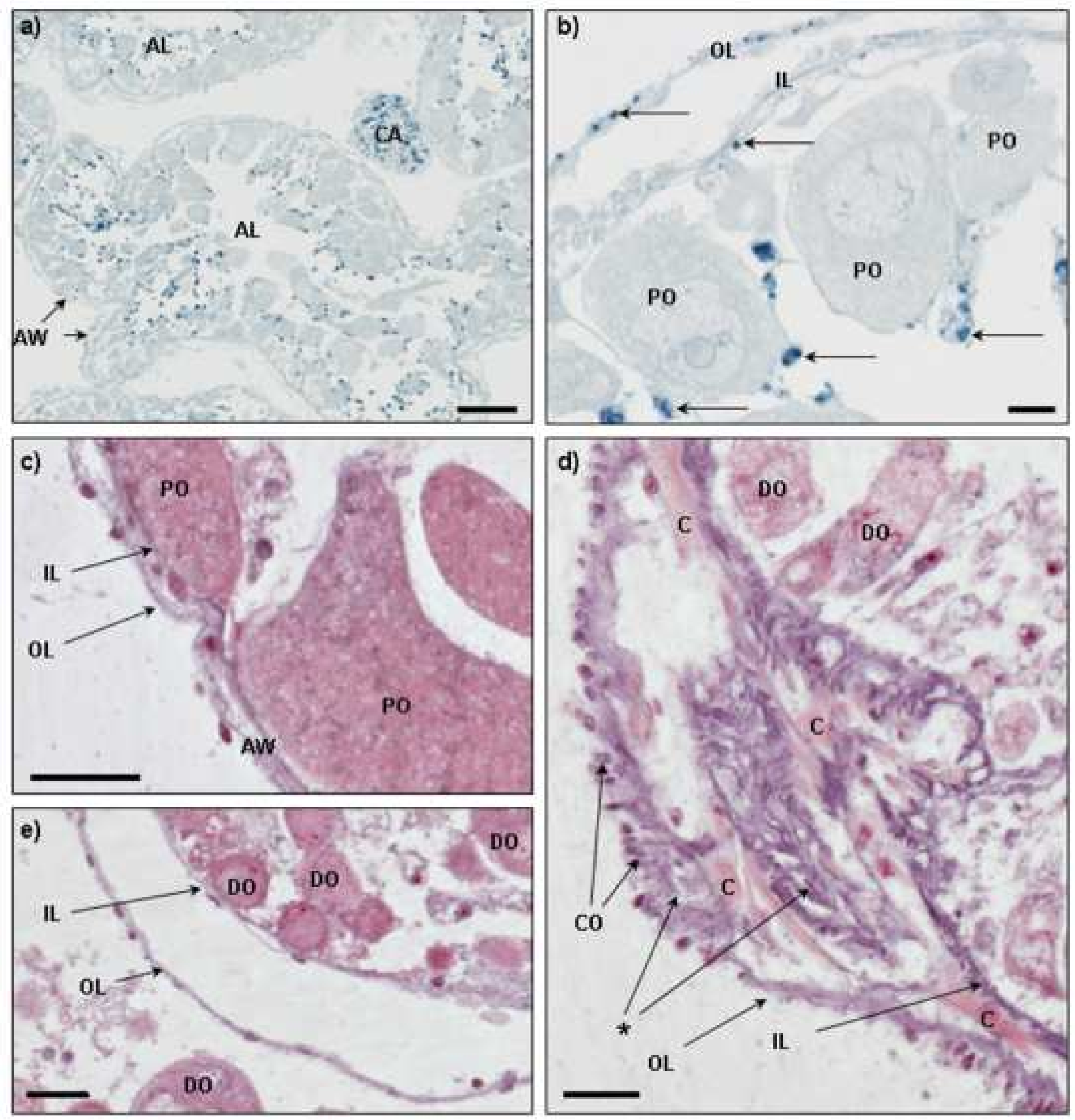